\title{
Effect of food-related behavioral activation therapy on food intake and the environmental impact of the diet: results from the MooDFOOD prevention trial
}

\author{
Alessandra C. Grasso ${ }^{1}$ D - Margreet R. Olthof ${ }^{1} \cdot$ Corné van Dooren $^{2} \cdot$ Miquel Roca $^{3} \cdot$ Margalida Gili $^{3}$. \\ Marjolein Visser ${ }^{1} \cdot$ Mieke Cabout $^{1} \cdot$ Mariska Bot $^{4} \cdot$ Brenda W. J. H. Penninx ${ }^{4} \cdot$ Gerard van Grootheest ${ }^{4}$. \\ Elisabeth Kohls ${ }^{5}$. Ulrich Hegerl ${ }^{6}$. Matthew Owens ${ }^{7}$. Ed Watkins ${ }^{7}$. Ingeborg A. Brouwer ${ }^{1}$ on behalf of the \\ MooDFOOD Prevention Trial Investigators
}

Received: 6 March 2019 / Accepted: 4 October 2019 / Published online: 23 October 2019

(c) The Author(s) 2019

\begin{abstract}
Purpose Food-based dietary guidelines are proposed to not only improve diet quality, but to also reduce the environmental impact of diets. The aim of our study was to investigate whether food-related behavioral activation therapy (F-BA) applying Mediterranean-style dietary guidelines altered food intake and the environmental impact of the diet in overweight adults with subsyndromal symptoms of depression.

Methods In total 744 adults who either received the F-BA intervention (F-BA group) or no intervention (control group) for 12 months were included in this analysis. Food intake data were collected through a food frequency questionnaire at baseline and after 6 and 12 months. Greenhouse gas emissions (GHGE), land use (LU), and fossil energy use (FEU) estimates from life-cycle assessments and a weighted score of the three ( $p$ ReCiPe score) were used to estimate the environmental impact of each individual diet at each timepoint.

Results The F-BA group reported increased intakes of vegetables (19.7 g/day; 95\% CI 7.8-31.6), fruit (23.0 g/day; 9.4-36.6), fish (7.6 g/day; 4.6-10.6), pulses/legumes (4.0 g/day; 1.6-6.5) and whole grains (12.7 g/day; 8.0-17.5), and decreased intake of sweets/extras ( $-6.8 \mathrm{~g} / \mathrm{day} ;-10.9$ to -2.8 ) relative to control group. This effect on food intake resulted in no change in GHGE, LU, and $p$ ReCiPe score, but a relative increase in FEU by $1.6 \mathrm{MJ} /$ day $(0.8,2.4)$.

Conclusions A shift towards a healthier Mediterranean-style diet does not necessarily result in a diet with reduced environmental impact in a real-life setting.

Trial registration ClinicalTrials.gov. Number of identification: NCT02529423. August 2015.
\end{abstract}

Keywords Sustainability $\cdot$ Diet $\cdot$ RCT $\cdot$ Depression

The members of the MooDFOOD Prevention Trial Investigators are listed in acknowledgements.

Electronic supplementary material The online version of this article (https://doi.org/10.1007/s00394-019-02106-1) contains supplementary material, which is available to authorized users.

Alessandra C. Grasso

alessandra.grasso@vu.nl

Extended author information available on the last page of the article

\section{Introduction}

A transition from traditional to current dietary patterns has contributed to a rise in global prevalence of chronic diseases and to unprecedented changes in ecosystems, both of which are threatening public health [1]. Food production is largely responsible for the environmental burdens associated with the human diet, including climate change, biodiversity loss, and pollution [2], with the other stages in the supply chain (i.e., processing, distribution, retailing, home food preparation, and waste) playing a part. Food production contributes to approximately $16-25 \%$ of total global greenhouse gas emissions (GHGE) [3], and it is estimated that this will increase by $51 \%$ from $2005 / 07$ to 2050 if dietary patterns 
do not change [4]. Currently croplands and pastures cover $37 \%$ of total land area [5], making agriculture the largest use of land on the planet. It is estimated that food production will need to increase by $25-70 \%$ to meet 2050 food demand [6]. While sustainable intensification of agriculture is proposed as a solution to increase food production with reduced environmental risks, it will not prevent further agricultural expansion driven by the projected demand [7]. Thus, dietary change has been identified as an essential counterpart to reduce the environmental pressures associated with the diet and to provide food security for future generations [8-10].

Recent research has increasingly focused on evaluating the environmental impact of habitual dietary choices, predefined diets, and alternative dietary patterns to propose more sustainable dietary patterns [1, 11-13]. An assortment of sustainable diets has been proposed, such as vegan and Mediterranean, as well as following national food-based dietary recommendations. Environmental as well as health benefits of these diets have been attributed to partial substitution of animal-based foods with plant-based foods [1, 12, 14, 15], and also to reduced caloric intake [16-19]. While these studies have predominately examined the environmental impact of hypothetical change from current to proposed diets, there is limited research on the environmental impact of dietary change in a real-life setting. Only one previous study has examined changes in GHGE related to changes in food choice in overweight women who received a diet plan based on the Nordic Nutrition Recommendations 2004 and found no effect on diet-associated GHGE, although the women increased their fruit and vegetable intake and decreased total caloric intake compared to those who did not receive the diet plan [20]. Thus, the environmental impact of dietary change in line with dietary guidelines in a real-life setting needs further investigation.

In the recent MooDFOOD (Multi-country cOllaborative project on the rOle of Diet, FOod-related behavior, and Obesity in the prevention of Depression) trial [21], 1025 overweight adults aged 18-75 years with subsyndromal symptoms of depression were randomized to a 12-month food-related behavioral activation therapy (F-BA) intervention (F-BA group) and were provided with dietary guidelines based on a Mediterranean-style diet (Table 1), or to a control group that received no F-BA intervention. Although the F-BA intervention was designed to change diet and behavior

Table 1 MooDFOOD dietary guidelines

\begin{tabular}{|c|c|}
\hline Food group & Guideline \\
\hline $\begin{array}{l}\text { Vegetables } \\
\text { Examples } \text { : green leafy and salad vegetables, fruit vegetables (e.g., cucumber and courgette), flower and flower buds } \\
\text { (e.g., broccoli), bulb and stem vegetables (e.g., onion); root and tubers; sea vegetables. Excludes potatoes }\end{array}$ & $300-400$ g/day \\
\hline $\begin{array}{l}\text { Fruit } \\
\text { Examples: core fruit, stone fruit, berries, citrus fruits, tropical fruits, dried fruit }\end{array}$ & 2-3 pieces/day \\
\hline $\begin{array}{l}\text { Fish } \\
\text { Examples: freshwater fish, salt water fish, white fish, oily fish, shell fish, sustainable fish }\end{array}$ & 3 times/week \\
\hline $\begin{array}{l}\text { Meat } \\
\text { Examples of good meat: chicken, turkey } \\
\text { Examples of protein-rich alternatives: eggs, nuts, soy products like tofu, fish }\end{array}$ & Reduce to $300 \mathrm{~g} /$ week \\
\hline $\begin{array}{l}\text { Pulses or legumes } \\
\text { Examples: soy beans, peanuts, fresh peas/beans, dried beans/peas, chickpeas, lentils }\end{array}$ & 3 times/week \\
\hline $\begin{array}{l}\text { Whole grain products } \\
\text { Examples: whole grain pasta and bread, brown rice, oatmeal, muesli, couscous }\end{array}$ & Choose \\
\hline $\begin{array}{l}\text { Low-fat dairy products } \\
\text { Examples: low-fat milk and yogurt, mature cheese, fresh cheese, soy products, cottage cheese }\end{array}$ & 3 servings/day \\
\hline $\begin{array}{l}\text { Olive oil } \\
\text { Examples of use: in frying food, tossed vegetables, salads, pasta sauces }\end{array}$ & $\begin{array}{l}\text { Use as principal } \\
\text { source for cooking }\end{array}$ \\
\hline $\begin{array}{l}\text { Processed foods and soft drinks } \\
\text { Examples: (frozen) ready-to-eat meals, processed sandwich meats, sausages, savory snacks, sweet snacks, fried food, } \\
\text { sugar-sweetened beverages, sugar added to coffee/tea, fruit juice } \\
\text { Examples of healthy alternatives: fruit, vegetables, nuts, fish, water, tea or coffee }\end{array}$ & Limit \\
\hline $\begin{array}{l}\text { Alcoholic beverages } \\
\text { Moderate consumption defined as: for men, maximum } 2 \text { standard glass per day; for women, maximum of } 1 \text { standard } \\
\text { glass per day }\end{array}$ & Drink in moderation \\
\hline
\end{tabular}

MooDFOOD dietary guidelines were based on a Mediterranean-style dietary pattern and provided in the food-related behavioral activation therapy (F-BA) intervention during the 12-month MooDFOOD depression prevention trial. Guidelines were provided orally and in the form of a pamphlet to the intervention participants [21]

${ }^{\text {a }}$ Examples of all food groups were provided with pictures along with practical tips to achieve the guideline 
to prevent the onset of depression, we hypothesized that the F-BA intervention would improve the environmental sustainability of the diet, as it focused on shifting habitual eating patterns to a Mediterranean-style diet [22]. Therefore, this study aimed to investigate whether the F-BA intervention changed food intake and to assess the environmental impact of the observed dietary change.

\section{Methods}

\section{Study design and subjects}

The MooDFOOD trial was a 12 -month randomized controlled prevention trial that investigated the feasibility and effectiveness of two different nutritional strategies for the prevention of depression: multi-nutrient supplementation and F-BA. The design, methods, and primary outcomes of the trial are described in detail elsewhere [21,23] and are summarized below. A sample of 1025 adults aged $18-75$ years with a body mass index (BMI) of $25-40 \mathrm{~kg} /$ $\mathrm{m}^{2}$ and elevated symptoms for depression (Patient Health Questionnaire-9 score $\geq 5$ ) [24] were recruited from The Netherlands, United Kingdom, Germany, and Spain and randomized to one of the four trial arms according to a $2 \times 2$ factorial design: (1) multi-nutrient supplement with F-BA intervention $(n=256)$; (2) placebo supplement with F-BA intervention ( $n=256)$; (3) multi-nutrient supplement without F-BA intervention ( $n=256)$; or (4) placebo supplement without F-BA intervention $(n=257)$. Randomization was stratified according to recruitment site (i.e., country) and participants' history of depression status at the baseline assessment. Participants, therapists, and researchers were blind to supplement allocation, and researchers were blind to behavioral intervention status when conducting analyses. The four trial arms were condensed to two trial arms to make comparisons in food intake between participants who received the F-BA intervention (F-BA group) and participants who did not receive the F-BA intervention (control group). We assumed that the multi-nutrient supplement had a null effect on food intake and thus was not a focus in this study. We confirmed this by adding supplement status to the statistical models when analyzing intervention effect and it did not affect results.

\section{F-BA intervention}

The F-BA intervention consisted of up to 21 therapy sessions, of which up to 15 were individual sessions and up to 6 were group sessions. The individual sessions were provided in single 30-min or double 1-h meetings occurring at first weekly and then every 2 weeks, while the group sessions included up to 10 people and lasted about $1 \mathrm{~h}$, occurring at first monthly and then bimonthly. Among the 512 participants randomized to the F-BA group, 71\% attended at least 8 out of the 21 sessions and were considered compliant (this cutoff for compliance is described by Bot et al. [23]). Participants attended a median of 14 out of 15 individual sessions [interquartile range (IQR) 6-15] and a median of 0 out of 6 group sessions (IQR 0-4) [23]. The control group received no F-BA intervention ( $n=513$ participants).

The F-BA intervention focused on changing food-related behaviors and shifting habitual dietary patterns to improve diet to prevent the onset of depressive episodes; environmental impact of diet was not considered in the design of the intervention. The F-BA intervention incorporated standard approaches of behavioral activation, which focuses on reducing avoidant behaviors and building routines and behaviors that are rewarding and/or pleasant, proven effective in the treatment of depression [25]. Psychologists familiar with behavioral activation were trained and delivered the F-BA intervention under supervision of a dietician. The psychologists helped participants to set goals on introducing healthy foods into their diets as well as reducing consumption of foods considered to be eaten in excess, taking into account baseline records. Goals were revisited and modified when necessary during subsequent sessions. During the intervention, participants kept a record of daily activities and habits, and were able to take notes about their mood and foods eaten during the day. The records aimed to help in the identification of triggers to habits and engagement in self-monitoring to improve food-related behaviors (e.g., regular meals per day, less snacking) and habitual dietary patterns. The participants were provided with a participant manual with detailed information about what was discussed.

\section{MooDFOOD dietary guidelines}

An introduction to healthy eating associated with mood improvement was provided in the third therapy session, which involved the provision of dietary guidelines based on a Mediterranean-style dietary pattern, referred to as the MooDFOOD dietary guidelines (Table 1). The Mediterranean diet served as the basis for the guidelines, because evidence indicates that following such a dietary pattern may prevent the onset of depression [26-31]. The guidelines were adjusted to be more consistent with the national dietary recommendations of the MooDFOOD prevention trial sites [32-36]. The MooDFOOD dietary guidelines consisted of general advice (e.g., limit meat intake to $300 \mathrm{~g} /$ week) and more detailed recommendations, and presented examples of 'good' and 'bad' food choices as well as food exchanges, for example, increase vegetable intake by decreasing intake of potatoes, rice, and/or bread; replace sugared drinks and sweet snacks by fruit; and replace processed sandwich meats by other sandwich toppings such as low-fat cheese, hummus, 
egg, and fish. No total calorie restriction was advised. In addition to the MooDFOOD dietary guidelines, a description of the link between diet and depression was provided in the F-BA participant manual, with greatest emphasis on the association between consumption of sweets, cakes, pastries, and fast foods and increased risk of depression and consumption of fruit, vegetables, fish, and whole grains and decreased risk of depression. Other foods in the MooDFOOD dietary guidelines such as low-fat dairy, meat, pulses/legumes, and olive oil were only described as part of a healthy diet, and no direct linkage between these foods and depression was made in the manual.

\section{Dietary data}

Participants reported their usual food intake during the previous month by completing an online self-administered food frequency questionnaire (FFQ) at baseline (T0), 6 months (T6) and at 12 months (T12; end of trial). The FFQ was based on the validated GA2LEN FFQ, as it showed to be an appropriate tool to estimate food intake across Europe regardless of cultural and linguistic differences [37]. The FFQ included 210 food items which were categorized into 18 food groups based on food groups for which dietary recommendations were made in the F-BA intervention: (1) vegetables, (2) fruit, (3) fish, (4) meat, (5) egg/soy, (6) pulses/ legumes, (7) nuts, (8) potatoes, (9) whole grains, (10) refined grains, (11) low-fat dairy products, (12) high-fat dairy products, (13) olive oil, (14) other fats/oils, (15) sweets/extras, (16) soft drinks (including fruit juices), (17) alcoholic beverages, and (18) water/coffee/tea (see Online Resource 1, Table 1 for FFQ food items and corresponding food group classification). Standard portion sizes following the Food Standard Agency Food Portion Sizes Guidelines were used [38]. Consumption frequency and portion size data were linked with food composition data from the McCance and Widdowson's composition of foods data set (2015) to calculate total energy intake in kilocalories ( $\mathrm{kcal})$ per gram $(\mathrm{g})$ [39]. The percentage of total energy intake $(E \%)$ contributed by each food group was calculated as the food group energy intake divided by the total energy intake. Food intake was considered missing if a participant completed $<15 \%$ of the FFQ. Among the 1025 participants randomized in the MooDFOOD depression prevention trial, 86 had missing dietary data at $\mathrm{T} 0$ and 186 had missing dietary data at both follow-up measurements and were excluded from this study. In addition, individuals who under-/over-reported caloric intake were excluded from the analysis. Energy under-/overreporting was classified as an energy intake spanning above or under the mean plus/minus three standard deviations (sd). Median intakes are reported along with the 25th and 75th percentiles.

\section{Environmental data}

Various measures were investigated to estimate the environmental impact of the diet, namely, GHGE expressed in kilograms of carbon dioxide equivalents $\left(\mathrm{kg} \mathrm{CO}_{2}\right.$-eq), land use (LU) in square meter-year $\left(\mathrm{m}^{2} * \mathrm{y}\right)$, fossil energy use (FEU) in mega joules (MJ), and a weighted score of the three ( $p$ ReCiPe score) [40]. GHGE, LU, and FEU were used as indictors due to their availability in reliable data sets and their frequent application in studies examining the environmental impact of diets [41]. Environmental impacts were calculated per $100 \mathrm{~g}$ food with life cycle assessments (LCA) from cradle-to-grave by Blonk Consultants (Gouda, The Netherlands) using ReCiPe 2016 Midpoint v1.00 method [42]. LCA is a methodological framework for assessing the environmental impacts over the entire life cycle of a product, from cultivation to packing, consumption and final disposal [43]. For each food item, GHGE, LU, and FEU data were obtained either from an LCA database containing 94 commonly eaten food products based on European Food Safety Authority's Comprehensive European Food Consumption Database (PROMISS data set 2017) [44] or a database containing 207 commonly eaten food products in The Netherlands, based on the Dutch Consumption Survey 2007-2010 (Optimeal data set 2015) [45]. A weighted combination of GHGE, LU, and FEU was used to calculate a $p$ ReCiPe score, a simplified environmental impact score, adapted from the $p$ ReCiPe score developed by Tyszler et al. [40]. The $p$ ReCiPe score of each food item was calculated by

$p \mathrm{ReCiPe}_{i}=0.0459 \times \mathrm{GHGE}_{i}+0.0439 \times \mathrm{LU}_{i}+0.0025 \times \mathrm{FEU}_{i}$, where $i$ is a food item and GHGE is expressed in $\mathrm{kg}$ $\mathrm{CO}_{2}$-eq/100 g, LU in $\mathrm{m}^{2} * \mathrm{y} / 100 \mathrm{~g}$, and FEU in $\mathrm{MJ} / 100 \mathrm{~g}$. This calculation is based on the ReCiPe method which aggregates several LCA impact categories, such as eutrophication and land transformation [46]. The $p \mathrm{ReCiPe}$ score only includes three of the 16 environmental impact categories (i.e., GHGE, LU and FEU), as they were found to have the most weight in the end score in LCAs of agricultural products $[15,41,47]$. Data were expressed per $100 \mathrm{~g}$ food and were used to estimate the overall GHGE, LU, FEU, and $p \mathrm{ReCiPe}$ score for each individual diet. Environmental data sources and values are available in Online Resource 2.

\section{Statistical analysis}

To analyze the difference in change in food intake and in environmental impact of the diet from $\mathrm{T} 0$ to $\mathrm{T} 12$ between the F-BA and control groups, longitudinal analysis of covariance using mixed model analysis was used. Participants with missing dietary data at T0 were excluded in the analyses, as the baseline value of the outcome variable was included 
as a covariate, as well as participants with missing dietary data at both $\mathrm{T} 6$ and T12 as individuals with only a baseline measurement are not part of the analysis [48]. Those with missing dietary data at either T6 or T12 were included in the analysis and no imputations were conducted, as mixed model analysis estimated with the maximum likelihood estimator accounts for missing data [49]. In addition to baseline outcome values, adjustment was made for sex (male or female), age (years, continuous), and site (added as another level to the model) for all outcomes. To assess the difference in change in environmental impact of the diet due to change in diet composition between the F-BA and control groups, adjustment for total caloric intake in kcal/day (continuous, time-dependent) was applied. However, since the environmental impact associated with the diet is influenced not only by diet composition, but also caloric quantity [17], the main environmental results presented do not control for caloric intake. To avoid the increased risk of type I error due to multiple testing of the 18 food groups, Holm-Bonferroni correction of the $P$ value was done [50]. This procedure is a sequential approach taking into account the total number of hypotheses (18 for 18 food groups), and original $P$ values, so that the corrected $P$ value for the $i$ th test is computed as $P_{\text {Holm-Bonferroni }}=(18-i+1) \leftarrow \S P[51]$. This was tested in order from the smallest to largest $P$ value and stopped when the first non-significant $P$ value was observed based on a $0.05 \alpha$ level. While original $P$ values are reported along with $95 \%$ confidence intervals (CI), statistical significance is determined by the Holm-Bonferonni adjusted $P$ value. The analyses were performed on an intention-to-treat (ITT) basis. Data were analyzed using Stata version 14.2 (StataCorp, TX, USA).

A post hoc per protocol (PP) analysis was done to examine whether those who were more compliant to the F-BA intervention had a greater change in diet and environmental impact of the diet. The cutoff for compliance was attending at least 8 out of the 21 sessions [23]. The same methods were used as in the ITT analysis, but the PP analyses measured the difference in change in food intake and environmental impact of the diet between a subgroup of compliant persons in the F-BA group and the control group over the 12-month period.

\section{Results}

\section{Study participants and baseline characteristics}

In total, 753 participants randomized in the MooDFOOD depression prevention trial had dietary data at $\mathrm{T} 0$ and at $\mathrm{T} 6$ or T12. The baseline mean \pm standard deviation of total caloric intake was $2483.9 \pm 2269.9 \mathrm{kcal} /$ day for men and $2347.2 \pm 1245.9 \mathrm{kcal} /$ day for women in both groups, resulting in an upper cutoff for implausible caloric intake of $9293.71 \mathrm{kcal} /$ day and $6084.78 \mathrm{kcal} / \mathrm{day}$, respectively. This led to the exclusion of 9 participants due to over-reporting caloric intake at either $\mathrm{T} 0$ or at both $\mathrm{T} 6$ and $\mathrm{T} 12$. Therefore, a total of 744 participants were included in the analyses measuring the intervention effect (flow diagram is available as Online Resource 1, Fig. 1). In general, baseline characteristics of those included in the analysis and those excluded from the analysis were comparable (Online Resource 1, Table 2).

Similar baseline characteristics of the two study groups were found and are presented in Table 2. The majority of the study participants were female $(75.4 \%)$ with a mean age of 47.6 years and BMI of $31.2 \mathrm{~kg} / \mathrm{m}^{2}$. The baseline median total caloric intake of the study participants was $2159.2 \mathrm{kcal} / \mathrm{day}$. The baseline median value of GHGE was $5.8 \mathrm{~kg} \mathrm{CO}_{2}$-eq/ day, LU $4.5 \mathrm{~m}^{2 *} \mathrm{y} / \mathrm{day}$, FEU $40.8 \mathrm{MJ} /$ day, and $p$ ReCipe 0.6 points in both groups. While contributing to $11.2 \mathrm{E} \%$, total meat intake accounted for approximately $35.1 \%$ of daily dietassociated GHGE, $39.1 \%$ of LU and $21.2 \%$ FEU in the F-BA group at baseline, with similar contributions in the control group (Table 3). The impact of dairy on GHGE, fat on LU and fish and vegetables on FEU was substantial (dairy: $14.1 \%$ of GHGE; fat: $10.9 \%$ of LU; fish: $16.5 \%$ of FEU and vegetables: $15.1 \%$ of FEU). Sweets/extras contributed most to total caloric intake in both groups at baseline $(19 \mathrm{E} \%)$, yet had a relatively low impact on GHGE (5.5\%), LU (7.0\%) and FEU (6.3\%).

\section{Changes in food intake and environmental impact of the diet during the intervention}

No difference in change in total caloric intake was apparent between the groups after 12 months $(22.9 \mathrm{kcal} /$ day; $95 \% \mathrm{CI}-10.1$ to $55.9 ; P=0.173)$. Significant increases in reported daily intake from $\mathrm{T} 0$ to $\mathrm{T} 12$ were observed for vegetables (19.7 g/day; 7.8-31.6; $P=0.001)$, fruit $(23.0 \mathrm{~g} /$ day; 9.4-36.6; $P=0.001)$, fish (7.6 g/day; 4.6-10.6; $P<0.001)$, pulses/legumes ( $4.0 \mathrm{~g} /$ day; $1.6-6.5, P=0.001)$, and whole grains $(12.7 \mathrm{~g} /$ day; $8.0-17.5, P<0.001)$, while a significant decrease was observed for sweets/extras $(-6.8 \mathrm{~g} /$ day; -10.9 to $-2.8 ; P=0.001)$ in the F-BA group relative to the control group (Fig. 1). Differences in change in reported intake of olive oil $(0.8 \mathrm{~g} /$ day; $0.2-1.4, P=0.006)$ and soft drinks $(-9.1 \mathrm{~g} /$ day; -18.1 to $-0.1, P=0.048)$ in the F-BA group relative to the control group were not significant after Holm-Bonferroni correction. No difference in change in reported meat consumption was evident, also when specifying red meat $(-3.4 \mathrm{~g} /$ day; -6.7 to $-0.04 ; P=0.047)$ and poultry $(1.7 \mathrm{~g} / \mathrm{day} ;-0.9$ to $4.4 ; P=0.197)$. The difference in change in red meat consumption was non-significant after Holm-Bonferroni correction. 
Table 2 Baseline characteristics of participants who received food-related behavioral activation therapy (F-BA) intervention (F-BA group) and participants who did not receive the F-BA intervention (control group) $(N=744)$

\begin{tabular}{|c|c|c|}
\hline Characteristic & $\begin{array}{l}\text { F-BA group } \\
n=373\end{array}$ & $\begin{array}{l}\text { Control group } \\
n=371\end{array}$ \\
\hline \multicolumn{3}{|l|}{$\operatorname{Sex}^{\mathrm{a}}$} \\
\hline Female & $78.3(292)$ & $72.5(269)$ \\
\hline Male & $21.7(81)$ & $27.5(102)$ \\
\hline Age $\left(\right.$ years) ${ }^{b}$ & $47.9 \pm 12.6$ & $47.2 \pm 13.4$ \\
\hline \multicolumn{3}{|l|}{ Education $^{\mathrm{a}}$} \\
\hline Low & $8.6(32)$ & $10.8(40)$ \\
\hline Middle & $47.5(177)$ & $46.9(174)$ \\
\hline High & $44.0(164)$ & $42.3(157)$ \\
\hline \multicolumn{3}{|l|}{ Site $^{\mathrm{a}}$} \\
\hline Germany & $29.0(108)$ & $31.8(118)$ \\
\hline United Kingdom & $24.1(90)$ & $25.3(94)$ \\
\hline Spain & $20.6(77)$ & $22.1(82)$ \\
\hline The Netherlands & $26.3(98)$ & $20.8(77)$ \\
\hline \multicolumn{3}{|l|}{ History of depression ${ }^{\mathrm{a}}$} \\
\hline Yes & $31.1(116)$ & $33.4(124)$ \\
\hline No & $68.9(257)$ & $66.6(247)$ \\
\hline \multicolumn{3}{|l|}{ Supplement status ${ }^{\mathrm{a}}$} \\
\hline Multi-nutrient supplement & 47.5 (177) & $49.1(182)$ \\
\hline Placebo & $52.5(196)$ & $50.9(189)$ \\
\hline BMI $\left(\mathrm{kg} / \mathrm{m}^{2}\right)^{\mathrm{b}}$ & $31.2 \pm 3.8$ & $31.2 \pm 4.1$ \\
\hline Total energy intake $(\mathrm{kcal} / \mathrm{day})^{\mathrm{c}}$ & $2167.8(1689.6 ; 2632.7)$ & $2155.0(1701.6 ; 2701.7)$ \\
\hline \multicolumn{3}{|l|}{ Food intake $(\mathrm{g} / \text { day })^{\mathrm{c}}$} \\
\hline Vegetables & $292.0(181.6 ; 437.1)$ & $302.5(219.6 ; 456.2)$ \\
\hline Fruit & $255.9(166.7 ; 412.6)$ & $260.0(165.7 ; 448.6)$ \\
\hline Fish & $44.3(27.1 ; 74.9)$ & $42.9(24.3 ; 70.0)$ \\
\hline Meat & $122.4(79.3 ; 185.6)$ & $135.0(86.1 ; 201.2)$ \\
\hline Egg/soy & $25.0(10.7 ; 42.9)$ & $27.9(14.3 ; 49.4)$ \\
\hline Pulses/legumes & $37.9(22.5 ; 62.1)$ & $35.7(21.8 ; 62.9)$ \\
\hline Nuts & $2.1(0.7 ; 5.0)$ & $2.1(0.7 ; 5.0)$ \\
\hline Potatoes & $24.5(13.9 ; 43.6)$ & $24.3(12.1 ; 46.5)$ \\
\hline Whole grains & $90.6(46.5 ; 156.6)$ & $92.8(43.6 ; 170.4)$ \\
\hline Refined grains & $98.6(62.6 ; 166.4)$ & $100.4(57.1 ; 163.3)$ \\
\hline Low-fat dairy & $120.0(17.1 ; 220.0)$ & $97.1(17.1 ; 237.1)$ \\
\hline High-fat dairy & $89.3(39.3 ; 160.4)$ & $94.3(46.1 ; 175.4)$ \\
\hline Olive oil & $9.4(3.1 ; 17.3)$ & $8.6(3.1 ; 13.4)$ \\
\hline Other fats/oils & $15.1(8.0 ; 27.5)$ & $14.8(7.1 ; 27.1)$ \\
\hline Sweets/extras & $117.0(70.3 ; 187.3)$ & $125.2(77.9 ; 189.9)$ \\
\hline Soft drinks & $85.7(28.6 ; 197.1)$ & $68.6(25.7 ; 200.0)$ \\
\hline Alcoholic beverages & $42.9(17.9 ; 114.3)$ & $45.4(8.9 ; 119.6)$ \\
\hline Water/coffee/tea & $1314.3(971.4 ; 1657.1)$ & $1300.0(914.3 ; 1700.0)$ \\
\hline \multicolumn{3}{|l|}{ Environmental indicators ${ }^{\mathrm{c}}$} \\
\hline $\mathrm{GHGE}^{\mathrm{d}}\left(\mathrm{kg} \mathrm{CO}_{2}\right.$-eq/day) & $5.73(4.47 ; 7.44)$ & $5.94(4.50 ; 7.84)$ \\
\hline $\mathrm{LU}^{\mathrm{e}}\left(\mathrm{m}^{2 *} \mathrm{y} /\right.$ day $)$ & $4.51(3.49 ; 5.81)$ & $4.61(3.49 ; 6.12)$ \\
\hline $\mathrm{FEU}^{\mathrm{f}}(\mathrm{MJ} /$ day $)$ & $40.33(31.89 ; 52.35)$ & $41.28(33.09 ; 56.95)$ \\
\hline$p \operatorname{ReCiPe}$ score $^{\mathrm{g}}$ (points/day) & $0.55(0.44 ; 0.74)$ & $0.58(0.45 ; 0.77)$ \\
\hline
\end{tabular}

${ }^{a}$ Values displayed as percentage (frequency)

${ }^{\mathrm{b}}$ Values displayed as mean $\pm \mathrm{SD}$

${ }^{c}$ Values displayed as median with interquartile range $(25 ; 75$ th percentile)

${ }^{\mathrm{d}}$ Greenhouse gas emission

${ }^{\mathrm{e}}$ Land use

${ }^{\mathrm{f}}$ Fossil energy use

${ }^{g}$ Weighted average of GHGE, LU and FEU 
Table 3 Food group contributions to total caloric intake $(E \%)$ and to daily dietassociated greenhouse gas emissions (GHGE) (\% of total $\mathrm{kg} \mathrm{CO}_{2}$-eq/day), land use (LU) (\% of total $\mathrm{m}^{2}$ \% $\mathrm{y} /$ day), and fossil energy use (FEU) (\% of total MJ/day) in the food-based behavioral activation therapy (F-BA) group and control group at baseline

\begin{tabular}{|c|c|c|c|c|c|c|c|c|}
\hline \multirow[t]{2}{*}{ Food group } & \multicolumn{4}{|c|}{ F-BA group $(N=373)$} & \multicolumn{4}{|c|}{ Control group $(N=371)$} \\
\hline & $E \%$ & GHGE & $\mathrm{LU}$ & FEU & $E \%$ & GHGE & $\mathrm{LU}$ & FEU \\
\hline Vegetables & 4.2 & 8.9 & 4.3 & 15.1 & 4.3 & 9.5 & 4.5 & 16.1 \\
\hline Fruit & 7.3 & 5.3 & 6.7 & 6.6 & 7.4 & 5.4 & 6.8 & 6.6 \\
\hline Fish & 3.4 & 9.6 & 1.6 & 16.5 & 3.2 & 8.9 & 1.4 & 15.3 \\
\hline \multicolumn{9}{|l|}{ Meat } \\
\hline Red meat & 8.7 & 30.0 & 31.8 & 15.9 & 9.3 & 30.5 & 33.0 & 16.6 \\
\hline Poultry & 2.5 & 5.1 & 7.3 & 5.3 & 2.5 & 5.1 & 7.4 & 5.3 \\
\hline Egg/soy & 2.5 & 1.3 & 2.3 & 1.7 & 2.7 & 1.4 & 2.5 & 1.9 \\
\hline Pulses/legumes & 2.1 & 1.2 & 3.8 & 1.7 & 2.2 & 1.2 & 3.9 & 1.7 \\
\hline Nuts & 1.3 & 0.2 & 1.0 & 0.3 & 1.4 & 0.3 & 0.9 & 0.3 \\
\hline Potatoes & 1.7 & 0.6 & 0.5 & 0.8 & 1.6 & 0.5 & 0.4 & 0.7 \\
\hline \multicolumn{9}{|l|}{ Cereals } \\
\hline Whole grains & 8.4 & 2.3 & 4.7 & 2.4 & 8.5 & 2.4 & 5.0 & 2.5 \\
\hline Refined grains & 9.0 & 3.0 & 2.5 & 3.6 & 8.8 & 2.9 & 2.4 & 3.4 \\
\hline \multicolumn{9}{|l|}{ Dairy } \\
\hline Low-fat dairy & 4.6 & 6.1 & 3.1 & 3.6 & 4.7 & 6.2 & 3.2 & 3.7 \\
\hline High-fat dairy & 8.1 & 8.0 & 4.4 & 3.9 & 7.9 & 7.7 & 4.3 & 3.8 \\
\hline \multicolumn{9}{|l|}{ Fat } \\
\hline Olive oil & 4.7 & 0.6 & 7.8 & 0.4 & 4.2 & 0.5 & 6.9 & 0.3 \\
\hline Other fats/oils & 5.2 & 1.9 & 3.1 & 1.3 & 5.0 & 1.8 & 3.0 & 1.2 \\
\hline Sweets/extras & 19.0 & 5.5 & 7.0 & 6.3 & 18.9 & 5.3 & 6.8 & 6.2 \\
\hline \multicolumn{9}{|l|}{ Beverages } \\
\hline Soft drinks & 0.8 & 1.6 & 1.8 & 2.8 & 0.8 & 1.5 & 1.6 & 2.5 \\
\hline Alcoholic & 2.5 & 2.4 & 2.4 & 3.3 & 2.5 & 2.5 & 2.4 & 3.4 \\
\hline Water/coffee/tea & 3.4 & 5.9 & 3.4 & 8.1 & 3.5 & 5.9 & 3.2 & 8.0 \\
\hline
\end{tabular}

These changes in food intake had no effect on diet-associated GHGE, LU or the $p$ ReCiPe score, but led to a statistically significant 3.6\% increase in FEU (1.6 MJ/day, 0.8-2.4, $P<0.001)$ in the F-BA group compared to the control group (Table 4). When the differences in change in environmental outcomes were controlled for total caloric intake, i.e., difference in change when energy intake would remain constant over the 12-month period between the F-BA group and the control group, the results were attenuated. However, the difference in change in FEU of the diet remained significant (1.2 MJ/day; 0.5-1.8; $P<0.001)$ and differences in change in GHGE, LU and $p$ ReCiPe score remained insignificant.

The difference in change in GHGE, LU, FEU, and $p$ ReCiPe of each food group as well as the overall diet are shown in the Online Resource 1, Figs. 2-5. The increase in fish intake by the F-BA group relative to the control group contributed the most to the increasing effect of the F-BA intervention on diet-associated FEU (Online Resource 1, Fig. 4). The relative increase in intake of fish contributed to an increase in FEU by $1.2 \mathrm{MJ} /$ day $(0.7-1.6 ; P<0.001)$, vegetables to an increase by $0.4 \mathrm{MJ} /$ day $(0.1-0.6 ; P=0.008)$, fruit to an increase by $0.2 \mathrm{MJ} /$ day $(0.1-0.04 ; P<0.001)$, whole grains to an increase by $0.1 \mathrm{MJ} /$ day $(0.1-0.2 ; P<0.001)$, and pulses/legumes to an increase by $0.1 \mathrm{MJ} /$ day $(0.03-0.10$;
$P=0.001)$, while the relative decrease in intake of sweets/ extras contributed to a decrease by $0.1 \mathrm{MJ} /$ day $(-0.2$ to $-0.1 ; P=0.001)$ in the F-BA group compared to the control group during the intervention.

\section{Post hoc per protocol analysis results}

In total, 365 out of 512 participants randomized to the F-BA intervention attended at least 8 therapy sessions and were considered compliant. Among those who attended at least 8 therapy sessions, 6 had missing dietary data at T0 and 45 had missing dietary data at both T6 and T12. In addition, 3 participants had over-reported energy intake at T0 and 1 participant at T6 and T12 were excluded from the analysis. Thus, 310 participants were included in the F-BA compliant subgroup. Indeed, the effect of the intervention was stronger among those who were most compliant to the F-BA intervention compared to the control group, i.e., a greater change in intake of the same food groups were observed compared to ITT analysis. Significant increases in reported daily intake from T0 to T12 were observed for vegetables (27.1 g/day; 14.9-39.3; $P<0.001)$, fruit ( $26.1 \mathrm{~g} / \mathrm{day}$; 12.0-40.2; $P<0.001)$, fish (9.9 g/day; 6.7-13.0; $P<0.001)$, pulses/legumes (5.2 g/day; 2.7-7.8, $P<0.001$ ), and whole 


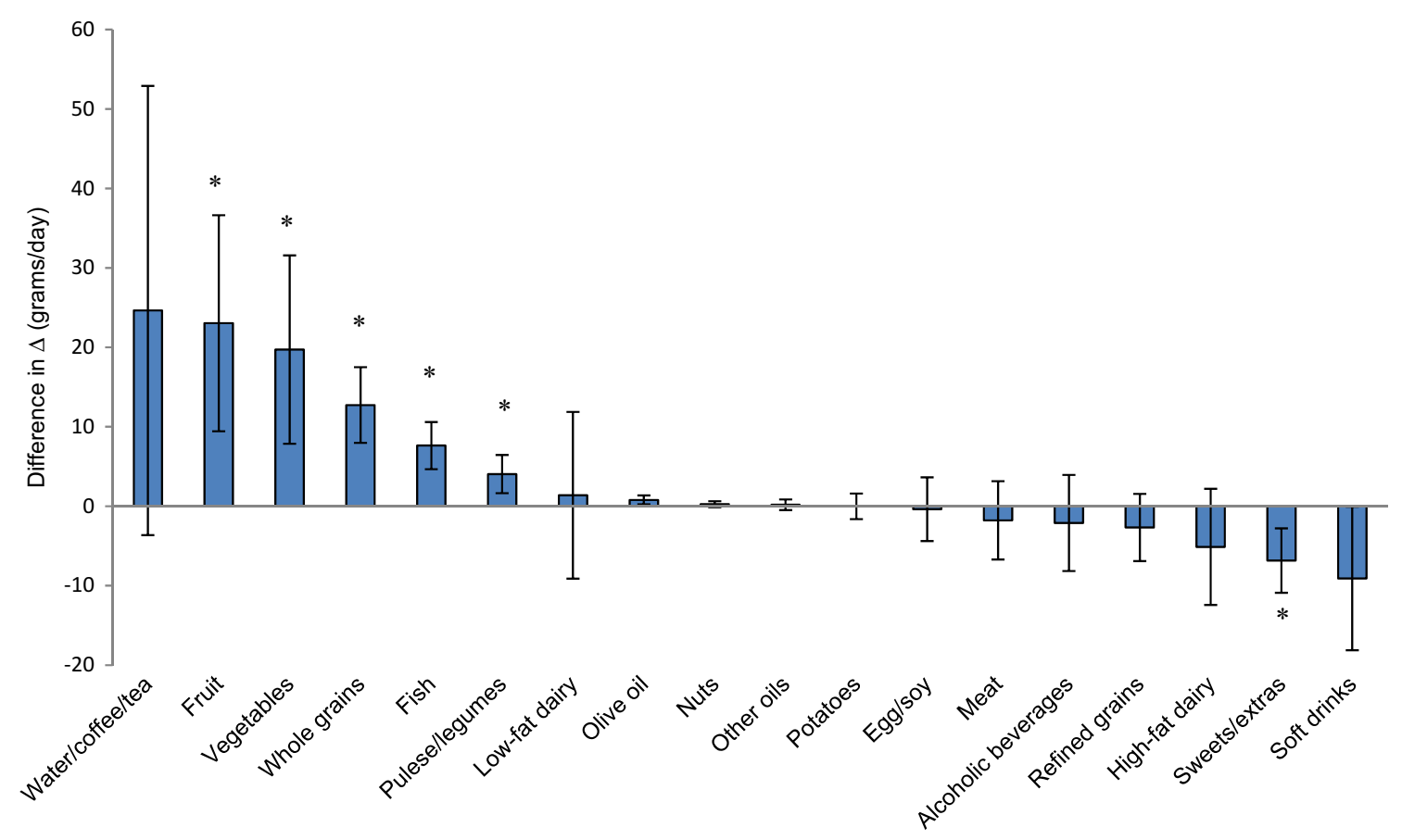

Fig. 1 Effect of the food-related behavioral activation therapy (F-BA) intervention on intake of 18 food groups in overweight adults with subsyndromal symptoms for depression during the 12-month MooDFOOD depression prevention trial $(N=744)$. The bars represent the difference in change in intake from baseline to 12 months between

grains (14.8 g/day; 9.7-19.9, $P<0.001)$, while a significant decrease was observed for sweets/extras $(-7.5 \mathrm{~g} /$ day; -11.7 to $-3.2 ; P=0.001)$ in the F-BA subgroup relative to the control group. This in turn led to a statistically significant 4.8\% increase in diet-associated FEU (2.2 MJ/day; 1.3-3.0; $P<0.001$ ), and no change in GHGE, LU, and $p$ ReCiPe score.

\section{Discussion}

We found that the F-BA intervention led to changes in food intake among overweight adults with subsyndromal symptoms of depression according to the MooDFOOD dietary guidelines: significant increases in consumption were reported for some of the food groups promoted (i.e., vegetables, fruit, fish, pulses/legumes, and whole grains) and a significant decrease was reported for one of the food groups discouraged (i.e., sweets/extras) by the guidelines. The differences in change are roughly equivalent to eating an additional 3/4 tablespoon of mixed vegetables a day, $3 / 4$ of an apple a day, 1/2 slice of whole grain bread a day, $1 \frac{1}{2}$ servings of salmon a month, and 31/4 tablespoons of legumes a month while refraining from eating about 2 teaspoons of sugar a day $[52,53]$. However, these dietary improvements resulted in an unfavorable increased FEU of the overall diet participants who received F-BA intervention (F-BA group) and participants who did not receive F-BA intervention (control group) when controlling for baseline value of outcome, age, sex and site. The lines represent $95 \%$ confidence intervals. *Significant at Holm-Bonferronicorrected $P$ value

equivalent to an additional $1.5 \mathrm{~L}$ of petrol a month [54], and no difference in change in diet-associated GHGE, LU or $p$ ReCiPe score. Our results indicate that a shift towards a healthier Mediterranean-style diet does not necessarily reduce diet-associated environmental impact in a real-life setting.

Our findings are consistent with other studies that modeled hypothetical dietary changes towards a healthier diet and observed either no change or an increase in environmental impact of the healthy diet scenarios [40, 55-58]. Such studies have found that there is a greater need for increasing consumption of vegetables, fruit, legumes, and fish than decreasing consumption of meat and dairy products to achieve a healthy diet, resulting in a net-positive effect on environmental impact of the diet (i.e., higher environmental impact). Yet, when meat consumption is substantially reduced, then the environmental benefits of reducing meat consumption outweigh the increase in environmental impact due to increased intake of vegetables, fruit, legumes, and fish when shifting towards a recommended healthy diet $[15,19]$. Although the MooDFOOD dietary guidelines recommended to limit meat intake to $300 \mathrm{~g} / \mathrm{week}$, which was substantially lower than the baseline median intake of $857 \mathrm{~g} /$ week in the F-BA group, the intervention did not lead to changes in meat intake. Because the current study observed the environmental impact of dietary changes in a real-life setting, it may 
Table 4 Effect of the food-related behavioral activation therapy (F-BA) intervention on environmental impact of diet in overweight adults with subsyndromal symptoms for depression during the 12-month MooDFOOD depression prevention trial $(N=744)$

\begin{tabular}{|c|c|c|c|c|}
\hline $\begin{array}{l}\text { Environmenta } \\
\text { outcomes }\end{array}$ & $\beta^{\mathrm{a}}$ & SE & $95 \% \mathrm{CI}$ & $P$ value \\
\hline \multicolumn{5}{|c|}{$\mathrm{GHGE}^{\mathrm{b}}$ ( $\mathrm{kg} \mathrm{CO}_{2}$-eq/day) } \\
\hline Model $1^{\mathrm{f}}$ & 0.060 & 0.060 & -0.058 to 0.179 & 0.320 \\
\hline Model $2^{\mathrm{g}}$ & 0.004 & 0.045 & -0.084 to 0.092 & 0.933 \\
\hline \multicolumn{5}{|c|}{$\mathrm{LU}^{\mathrm{c}}\left(\mathrm{m}^{2 *} \mathrm{y} /\right.$ day $)$} \\
\hline Model 1 & 0.024 & 0.049 & -0.071 to 0.119 & 0.622 \\
\hline Model 2 & -0.017 & 0.035 & -0.084 to 0.051 & 0.630 \\
\hline \multicolumn{5}{|l|}{$\mathrm{FEU}^{\mathrm{d}}(\mathrm{MJ} /$ day $)$} \\
\hline Model 1 & 1.625 & 0.418 & 0.807 to 2.444 & $<0.001 *$ \\
\hline Model 2 & 1.118 & 0.323 & 0.547 to 1.815 & $<0.001 *$ \\
\hline \multicolumn{5}{|c|}{$p$ ReCiPe score ${ }^{\mathrm{e}}$ (points) } \\
\hline Model 1 & 0.008 & 0.006 & -0.003 to 0.019 & 0.173 \\
\hline Model 2 & 0.002 & 0.004 & -0.006 to 0.010 & 0.460 \\
\hline
\end{tabular}

*Significant at Holm-Bonferroni-corrected $P$ value

${ }^{a}$ Unstandardized beta coefficient of difference in change from baseline to 12 months between participants who received the F-BA intervention (F-BA group) and participants who did not receive the F-BA intervention (control group)

${ }^{\mathrm{b}}$ Greenhouse gas emissions

${ }^{c}$ Land use

${ }^{\mathrm{d}}$ Fossil energy use

${ }^{\mathrm{e}}$ Weighted average of GHGE, LU and FEU

${ }^{\mathrm{f}}$ Model 1 controls for baseline value of outcome, age, sex and site

${ }^{\mathrm{g}}$ Model 2 is model 1 plus total caloric intake as a covariate

inherently encounter constraints such as individual preferences, values, and personal efficacy not accounted for in the previous studies examining the environmental impact of hypothetical dietary change. Consumer behavior studies that have explored attitudes and intentions towards meat consumption have found that there is low willingness to change meat consumption behavior in terms of reducing or substituting meat in Europe [59,60]. For many people meat holds an important place in the diet as it is associated with pleasure and various personal, social, and cultural-oriented values such as health and strength [60,61]. Therefore, future dietary interventions should consider current values attached to meat and other constraints opposing changes in meat consumption to achieve healthy, sustainable diets.

We found that the increased impacts on GHGE and LU from the increased intake of fruit, vegetables, fish, pulses/ legumes, and whole grains were collectively offset by the reduced impacts on GHGE and LU from the decreased intake of sweets/extras. Our results are in line with the weight loss trial which found that a reduction in intake of sweets, snacks, and soft drinks and an increase in intake of fruit and vegetables led to no change in overall carbon footprint of the diet [20]. However, we found that observed dietary change led to an increase in FEU of the overall diet, which may be attributable to the relative increase in fish, as fisheries are generally energy-intensive operations $[62,63]$. An additional explanation for finding an increase in FEU of the overall diet may be due to the relative increase in vegetable consumption combined with the use of environmental data from the Netherlands, where the impact of vegetables on FEU is relatively high because of the use of greenhouses running on fossil energy [64]. Similar changes in FEU were found in two modeling studies, which found that switching from the current average American diet to a healthy diet recommended in the Dietary Guidelines for Americans would increase FEU, mainly caused by the recommendation to substantially increase the intake of fruits, vegetables and dairy products $[57,58]$. Thus, while the increase in consumption of fruit, vegetables, fish, pulses/legumes, and whole grains may make a diet healthier, it may make it less sustainable unless replacing other food groups with similar or higher environmental impact, i.e., meat.

The actual change in the environmental impact of the diet is highly sensitive to the change in food choices, since there is very large variation in the GHGE, LU, and FEU levels per unit food within both the animal-based and plant-based food groups [11, 55]. To achieve healthy and sustainable diets, future dietary interventions must consider the environmental impact associated with different food groups (e.g., high-impact meat versus low-impact legumes), and also the environmental impact of various foods within food groups, such as beef (high impact) and poultry (lower impact) or tomatoes grown in a greenhouse (high impact) or in a field (lower impact) [55, 65]. As there are many different ways to follow the dietary guidelines provided by the MooDFOOD trial, different choices within food groups, for example, how to meet $300-400 \mathrm{~g}$ of vegetables per day, can lead to different environmental impacts. This was illustrated by Van Kamp and colleagues who found that compared to the current average Dutch diet, two healthy diets defined by the Dutch dietary recommendations resulted in either a $3 \%$ or $28 \%$ reduction in GHGE, with greater reductions in GHGE when dietary recommendations were met by including only foods with low impact on GHGE [55]. Furthermore, a reduction in overall caloric intake without changing the composition of the diet has been shown to result in lower environmental impact of the diet $[16,58]$. Thus, for dietary guidelines to have a positive impact on the environment as well as health, consideration of the environmental impact of individual foods and food groups as well as total caloric intake is needed in addition to health considerations.

Our study has some limitations. First, FFQs are prone to recall bias and selective misreporting of consumption of certain foods [66]. In particular, the potential of differential response bias is high as exposure to the intervention itself can 
create differential error in reporting, with the treatment group possibly over-reporting foods promoted during the F-BA intervention (e.g., vegetables) and under-reporting foods that were discouraged (e.g., sweets) compared to the control group [67]. Second, the study population was overweight and at high risk of depression, limiting the generalizability of our findings to other populations. Third, the LCA data used to estimate the environmental impact of the diet comprised of a mix of data representative of an average Dutch diet as well as an average European diet. There are differences in geography, climate and production, processing, and distribution systems in Germany, UK, Spain and The Netherlands which may influence the actual environmental impact of diets in each country. Thus, while the LCA data used does not explicitly represent the production practices in each country, in the absence of country-specific data, these data serve as a proxy to provide a rough estimation on diet-level impacts. Fourth, while the LCA data sets used allowed us to study multiple environmental impact indicators, namely, GHGE, LU, and FEU, other important aspects such as water use, eutrophication, and biodiversity loss are missing in this analysis, because reliable data were not available. For instance, GHGE, LU, and FEU do not reflect the sustainability concerns of increasing fish consumption with regard to marine biodiversity loss and overfishing. Finally, the studied environmental indicators also have limitations. The LU indicator does not differentiate between different types and quality of land, which will bias livestock products to having higher impacts even if they graze on land unsuitable for cropping [2]. Furthermore, GHGE and FEU are strongly correlated $(0.913, P<0.001)$, as carbon dioxide emitted from fossil fuels used in the food chain directly contributes to GHGE of the diet [63]. Despite the considerable overlap between these two indicators, they measure different pressures, i.e., GHGE is a proxy for polluting emissions and FEU is a proxy for resource depletion [41, 68]. The strengths of this study include the use of an FFQ validated to measure food intake across different European countries [37], its large sample size compared to other dietary interventions looking at changes in food intake [69] and the use of three environmental impact indicators in addition to a weighted score measuring the overall environmental impact. Most importantly, the MooDFOOD trial allowed for the assessment of environmental impact of dietary change under real-life circumstances, while the previous studies have mainly measured the environmental impact of hypothetical dietary change.

\section{Conclusion}

Our research shows that the food-related behavioral activation therapy led to favorable changes in food intake according to the Mediterranean-style dietary guidelines, but to no change in GHGE, LU or $p$ ReCiPe score, and a small unfavorable change in FEU of the diet. To generate dietary change that is favorable for both health and the environment, dietary interventions must focus specifically on incorporating environmental sustainability aspects, in particular focusing on reducing and replacing meat consumption, choosing foods within a healthy diet that have low environmental impact and reducing total caloric intake. Furthermore, cultural, social and personal values around eating meat should be integrated. Future research should evaluate the environmental impact of dietary change in individuals who receive dietary guidelines especially designed to decrease the environmental impact of the diet and improve health, simultaneously.

Acknowledgements Funding for this article is provided by the European Union 7th Framework Program (FP) MooDFOOD Project 'Multicountry cOllaborative project on the rOle of Diet, FOod-related behaviour, and Obesity in the prevention of Depression' (grant agreement no. 613598). This work is supported in the UK by the National Institute for Health Research (NIHR), through the Primary Care Research Network and the NIHR Exeter Clinical Research Facility. The authors would like to thank all participants for their participation in the trial. The members of the MooDFOOD prevention trial investigators are: MooDFOOD project coordination, VU University Amsterdam, Department of Health Sciences, the Netherlands. Prof. Marjolein Visser, $\mathrm{Ph} . \mathrm{D}$.-Principle Investigator of the MooDFOOD project and the MooDFOOD prevention trial. Prof. Ingeborg A Brouwer, Ph.D.-CoPrinciple Investigator of the MooDFOOD project and the MooDFOOD prevention trial. Mieke Cabout-Project manager of the MooDFOOD project. Trial Centers: VU Medical Center, Amsterdam, the Netherlands, Prof. Brenda Penninx, Ph.D.-Field Center Principal Investigator. Dr. Mariska Bot, Ph.D.--Field Center Co-Investigator. Nadine Paans-Field Center therapist and research assistant. Carisha Thesing-Field Center therapist. Deborah Gibson-Smith-Field Center research assistant. Melany Horsfall-Field Center coordinator. Lena Weiss-Field Center research assistant. University of Exeter, Exeter, United Kingdom, Prof. Ed Watkins, Ph.D.-Field Center Principal Investigator, lead for developing the MooDFOOD Food-related Behavioural Change Intervention. Dr. Matthew Owens, Ph.D.-Field Center Co-Investigator. Dr. Amy Romijn, Ph.D.-Field Postdoctoral Research Associate. Hannah Bunce-Field Center Associate Research Fellow. Owain Winfield-Field Center Researcher and Therapist. University of Balearic Islands, Palma de Mallorca, Spain: Prof. Miquel Roca, Ph.D., MD—Field Center Principal Investigator. Prof. Margarita Gili, Ph.D.-Field Center Co-Investigator, co-lead for developing the MooDFOOD Food-related Behavioural Change Intervention. Prof. Miquel Tortella, Ph.D.-Field Center-Co-Investigator, co-lead for developing the MooDFOOD Food-related Behavioural Change Intervention. Clara Homar Covas-Field Center Researcher and therapist, Margalida Vives Forteza-Field Center Research assistant, Adoración Castro Gracia-Field Center Research assistant. Maria Angeles PérezAra-Field Center Research assistant. José Luis Reig-Field Center therapist. University Leipzig, Leipzig, Germany: Prof. Ulrich Hegerl, MD_Field Center Principal Investigator, Dr. Elisabeth Kohls, Ph.D.Field Center Co-Investigator, Jana Hoesel-Field Center study nurse, Ezgi Dogan, MD—Field Center research fellow, Sabrina BaldofskiField Center therapist, Nicole Mauche-Field Center therapist. Data Management, GGZ inGeest, Amsterdam the Netherlands: Prof. Brenda Penninx, Ph.D.-Principal investigator, Gerard van Grootheest-Data management coordinator, Bep Verkerk-Data manager 
Author contributions ACG was the lead author on the manuscript and ACG analyzed and interpreted the data with IAB, MRO, and CD. MV and $\mathrm{IAB}$ obtained funding for the MooDFOOD project, designed the MooDFOOD prevention trial and together with MC coordinated the MooDFOOD project. BWP, MB, and EW contributed to the design of the MooDFOOD prevention trial. EW led the development and training of the MooDFOOD Food-related Behavioral Change Intervention. EK and $\mathrm{UH}$ coordinated the recruitment, interventions, and follow-ups at the trial center in Germany, University Leipzig. BWP and MB coordinated the recruitment, interventions, and follow-ups at the trial center in the Netherlands, VU University Medical Center Amsterdam. EW and $\mathrm{MO}$ coordinated the recruitment, interventions, and follow-ups at the trial center in the United Kingdom, University of Exeter. MR and MG coordinated the recruitment, interventions and follow-ups at the trial center in Spain, University of Balearic Islands. GvG set up the logistics for the trial's data collection. All authors contributed to the writing of the manuscript and approved the final version. Please, see www.moodfood-vu.eu for a complete list of the MooDFOOD Prevention Trial Investigators

\section{Compliance with ethical standards}

Conflict of interest The authors declare that they have no conflict of interest.

Ethical standards The trial was performed in accordance with the principles of Good Clinical Practice. Institutional review board approval was obtained from the Research Ethics Committee Govern de les Illes Balears, Palma, Spain (10th of March 2015), the Ethics Committee of the University of Leipzig, Germany (2nd of April 2015), VU Medical Center Amsterdam, the Netherlands (8th of July, 2015) and the NHS National Research Ethics Service (NRES) Committee, SouthWest, UK (Research Ethics Committee number-15/SW/0153) for University of Exeter (3th of August 2015). All individuals gave their informed consent prior to inclusion in the study.

Open Access This article is distributed under the terms of the Creative Commons Attribution 4.0 International License (http://creativeco mmons.org/licenses/by/4.0/), which permits unrestricted use, distribution, and reproduction in any medium, provided you give appropriate credit to the original author(s) and the source, provide a link to the Creative Commons license, and indicate if changes were made.

\section{References}

1. Tilman D, Clark M (2014) Global diets link environmental sustainability and human health. Nature 515:518-522. https://doi. org/10.1038/nature13959

2. Foley JA, Ramankutty N, Brauman KA, Cassidy ES, Gerber JS, Johnston $\mathrm{M}$ et al (2011) Solutions for a cultivated planet. Nature 478:337-342. https://doi.org/10.1038/nature10452

3. Vermeulen SJ, Campbell BM, Ingram JSI (2012) Climate change and food systems. Annu Rev Environ Resour 37(1):195-222. https ://doi.org/10.1146/annurev-environ-020411-130608

4. Springmann M, Godfray HCJ, Rayner M, Scarborough P (2016) Analysis and valuation of the health and climate change cobenefits of dietary change. Proc Natl Acad Sci USA 113(15):4146-4151. https://doi.org/10.1073/pnas.1523119113

5. FAOSTAT (2015) FAO Statistical Databases (FAOSTAT). http:// faostat.fao.org/. Accessed 05 July 2018
6. Hunter MC, Smith RG, Schipanski ME, Atwood LW, Mortensen DA (2017) Agriculture in 2050: recalibrating targets for sustainable intensification. Bioscience 67(4):386-391. https://doi. org/10.1093/biosci/bix010

7. Bajželj B, Richards KS, Allwood JM, Smith P, Dennis JS, Curmi $E$ et al (2014) Importance of food-demand management for climate mitigation. Nat Clim Change 4:924-929. https://doi. org/10.1038/nclimate2353

8. Bryngelsson D, Wirsenius S, Hedenus F, Sonesson U (2016) How can the EU climate targets be met? A combined analysis of technological and demand-side changes in food and agriculture. Food Policy 59:152-164. https://doi.org/10.1016/j.foodp ol.2015.12.012

9. Springmann M, Clark M, Mason-D'Croz D, Wiebe K, Bodirsky BL, Lassaletta L et al (2018) Options for keeping the food system within environmental limits. Nature. https://doi.org/10.1038/ s41586-018-0594-0

10. Röös E, Bajželj B, Smith P, Patel M, Little D, Garnett T (2017) Greedy or needy? Land use and climate impacts of food in 2050 under different livestock futures. Glob Environ Change 47:1-12. https://doi.org/10.1016/j.gloenvcha.2017.09.001

11. Hallström E, Carlsson-Kanyama A, Börjesson P (2015) Environmental impact of dietary change: a systematic review. J Clean Prod 91:1-11. https://doi.org/10.1016/j.jclepro.2014.12.008

12. Aleksandrowicz L, Green R, Joy EJM, Smith P, Haines A (2016) The impacts of dietary change on greenhouse gas emissions, land use, water use, and health: a systematic review. PLoS One 11(11):e0165797. https://doi.org/10.1371/journal.pone.0165797

13. Perignon M, Vieux F, Soler L-G, Masset G, Darmon N (2017) Improving diet sustainability through evolution of food choices: review of epidemiological studies on the environmental impact of diets. Nutr Rev 75(1):2-17. https://doi.org/10.1093/nutrit/nuw04 3

14. Nelson ME, Hamm MW, Hu FB, Abrams SA, Griffin TS (2016) Alignment of healthy dietary patterns and environmental sustainability: a systematic review. Adv Nutr 7(6):1005-1025. https://doi. org/10.3945/an.116.012567

15. van Dooren $\mathrm{C}$, Marinussen $\mathrm{M}$, Blonk $\mathrm{H}$, Aiking $\mathrm{H}$, Vellinga $\mathrm{P}$ (2014) Exploring dietary guidelines based on ecological and nutritional values: a comparison of six dietary patterns. Food Policy 44:36-46. https://doi.org/10.1016/j.foodpol.2013.11.002

16. Springmann M, Wiebe K, Mason-D'Croz D, Sulser TB, Rayner M, Scarborough P (2018) Health and nutritional aspects of sustainable diet strategies and their association with environmental impacts: a global modelling analysis with country-level detail. Lancet Planet Health 2(10):e451-e461. https://doi.org/10.1016/ S2542-5196(18)30206-7

17. Masset G, Vieux F, Verger EO, Soler L-G, Touazi D, Darmon N (2014) Reducing energy intake and energy density for a sustainable diet: a study based on self-selected diets in French adults. Am J Clin Nutr 99(6):1460-1469. https://doi.org/10.3945/ ajen.113.077958

18. van Dooren C, Keuchenius C, de Vries JHM, de Boer J, Aiking $H$ (2018) Unsustainable dietary habits of specific subgroups require dedicated transition strategies: evidence from the Netherlands. Food Policy 79:44-57. https://doi.org/10.1016/j.foodp ol.2018.05.002

19. Behrens P, Kiefte-de Jong JC, Bosker T, Rodrigues JFD, de Koning A, Tukker A (2017) Evaluating the environmental impacts of dietary recommendations. Proc Natl Acad Sci USA 114(51):13412. https://doi.org/10.1073/pnas.1711889114

20. Huseinovic E, Ohlin M, Winkvist A, Bertz F, Sonesson U, Brekke HK (2017) Does diet intervention in line with nutrition recommendations affect dietary carbon footprint? Results from a weight loss trial among lactating women. Eur J Clin Nutr 71(10):12411245. https://doi.org/10.1038/ejen.2017.63 
21. Roca M, Kohls E, Gili M, Watkins E, Owens M, Hegerl U et al (2016) Prevention of depression through nutritional strategies in high-risk persons: rationale and design of the MooDFOOD prevention trial. BMC Psychiatry 16(1):192. https://doi.org/10.1186/ s12888-016-0900-z

22. Dernini S, Berry EM (2015) Mediterranean diet: from a healthy diet to a sustainable dietary pattern. Front Nutr. https://doi. org/10.3389/fnut.2015.00015

23. Bot M, Brouwer IA, Roca M, Kohls E, Penninx BWJH, Watkins E et al (2019) Effect of multinutrient supplementation and food-related behavioral activation therapy on prevention of major depressive disorder among overweight or obese adults with subsyndromal depressive symptoms: the MooDFOOD Randomized Clinical Trial. JAMA 321(9):858-868. https://doi.org/10.1001/ jama.2019.0556

24. Kroenke K, Spitzer RL, Williams JBW (2001) The PHQ9. J Gen Intern Med 16(9):606-613. https://doi.org/10.104 6/j.1525-1497.2001.016009606.x

25. Cuijpers P, van Straten A, Warmerdam L (2007) Behavioral activation treatments of depression: a meta-analysis. Clin Psychol Rev 27(3):318-326. https://doi.org/10.1016/j.cpr.2006.11.001

26. Jacka FN, Pasco JA, Mykletun A, Williams LJ, Hodge AM, O'Reilly SL et al (2010) Association of Western and traditional diets with depression and anxiety in women. Am J Psychiatry 167(3):305-311. https://doi.org/10.1176/appi.ajp.2009.09060881

27. Akbaraly TN, Brunner EJ, Ferrie JE, Marmot MG, Kivimaki M, Singh-Manoux A (2009) Dietary pattern and depressive symptoms in middle age. Br J Psychiatry 195(5):408-413. https://doi. org/10.1192/bjp.bp.108.058925

28. Rienks J, Dobson AJ, Mishra GD (2013) Mediterranean dietary pattern and prevalence and incidence of depressive symptoms in mid-aged women: results from a large community-based prospective study. Eur J Clin Nutr 67(1):75-82. https://doi.org/10.1038/ ejcn.2012.193

29. Skarupski KA, Tangney CC, Li H, Evans DA, Morris MC (2013) Mediterranean diet and depressive symptoms among older adults over time. J Nutr Health Aging 17(5):441-445. https://doi. org/10.1007/s12603-012-0437-x

30. Mamplekou E, Bountziouka V, Psaltopoulou T, Zeimbekis A, Tsakoundakis N, Papaerakleous N et al (2010) Urban environment, physical inactivity and unhealthy dietary habits correlate to depression among elderly living in eastern Mediterranean islands: the MEDIS (MEDiterranean ISlands Elderly) study. J Nutr Health Aging 14(6):449-455. https://doi.org/10.1007/s12603-010-0091-0

31. Nicolaou M, Colpo M, Vermeulen E, Elstgeest LEM, Cabout M, Gibson-Smith D et al (2019) Association of a priori dietary patterns with depressive symptoms: a harmonised meta-analysis of observational studies. Psychol Med. https://doi.org/10.1017/ S0033291719001958

32. Council Health (2006) Guidelines for Good Nutrition 2006 (in Dutch). Gezondheidsraad, The Hague

33. German Nutrition Society (2004) The nutrition report 2004. Deutsche Gesellschaft für Ernährung e.V, Bonn

34. Spanish Society of Community Nutrition (2004) Guía de la alimentación saludable (in Spanish). Sociedad Española de Nutrición Comunitaria (SENC), Madrid

35. Food Standards Agency (FSA) (2007) FSA nutrient and food based guidelines for UK institutions. Food Standards Agency, London

36. World Health Organization (WHO) (2003) Food based dietary guidelines in the WHO European Region. WHO, Copenhagen

37. Garcia-Larsen V, Luczynska M, Kowalski ML, Voutilainen H, Ahlström M, Haahtela T et al (2011) Use of a common food frequency questionnaire (FFQ) to assess dietary patterns and their relation to allergy and asthma in Europe: pilot study of the
GA2LEN FFQ. Eur J Clin Nutr 65:750. https://doi.org/10.1038/ ejcn.2011.15

38. Food Standard Agency (2006) Food Portion Sizes Guidelines, 3rd edn. FSA, London

39. Roe M, Pinchen H, Church S, Finglas P (2015) McCance and Widdowson's the composition of foods seventh summary edition and updated composition of foods integrated dataset. Nutr Bull 40(1):36-39. https://doi.org/10.1111/nbu.12124

40. Tyszler M, Kramer G, Blonk H (2016) Just eating healthier is not enough: studying the environmental impact of different diet scenarios for Dutch women (31-50 years old) by linear programming. Int J LCA 21(5):701-709. https://doi.org/10.1007/s1136 7-015-0981-9

41. van Dooren C, Aiking H, Vellinga P (2018) In search of indicators to assess the environmental impact of diets. Int J LCA 23(6):1297-1314. https://doi.org/10.1007/s11367-017-1371-2

42. Huijbregts MAJ, Steinmann ZJN, Elshout PMF, Stam G, Verones F, Vieira MDM et al (2016) ReCiPe 2016: a harmonized life cycle impact assessment method at midpoint and endpoint level report I: characterization. National Institute for Public Health and the Environment, Bilthoven

43. Joint Research Centre (JRC) (2010) ILCD handbook: general guide for life cycle assessment-detailed guidance. European Commission, Joint Research Centre, Institute for Environment and Sustainability, Ispra

44. European Food Safety Authority (2011) Use of the EFSA comprehensive european food consumption database in exposure assessment. EFSA J 9(3):2097. https://doi.org/10.2903/j.efsa.2011.2097

45. Van Rossum CTM, Fransen HP, Verkaik-Kloosterman J, BuurmaRethans EJM, Ocké MC (2011) Dutch National Food Consumption Survey 2007-2010. Diet of children and adults aged 7-69 years. National Institute for Public Health and the Environment, Bilthoven

46. Goedkoop M, Heijungs R, Huijbregts M, De Schryver A, Struijs J, Van Zelm R (2009) ReCiPe 2008: A life cycle impact assessment method which comprises harmonised category indicators at the midpoint and the endpoint level; report 1: characterisation, 1st edn. Ministry of Housing, Spatial Planning and Environment, The Hague

47. Sevenster MN, Blonk H, Van der Flier S (2010) Milieuanalyses Voedsel en Voedselverliezen (Environmental analysis of food and food losses). CE Delft, Blonk Milieu Advies, Delft

48. Twisk J, Bosman L, Hoekstra T, Rijnhart J, Welten M, Heymans M (2018) Different ways to estimate treatment effects in randomised controlled trials. Contemp Clin Trials Commun 10:80 85. https://doi.org/10.1016/j.conctc.2018.03.008

49. Twisk J (2013) Applied longitudinal data analysis for epidemiology: a practical guide, 2nd edn. Cambridge University Press, Cambridge

50. Holm S (1979) A simple sequentially rejective multiple test procedure. Scand J Stat 6(2):65-70. http://www.jstor.org/stable/46157 33

51. Abdi H (2010) Holm's sequential bonferroni procedure. In: Salkind N (ed) Encyclopedia of research design. SAGE Publications Inc, Thousand Oaks, pp 574-577. https://doi.org/10.4135/97814 12961288.n178

52. The British Dietetic Association (BDA) (2016) Food fact sheet. https://www.bda.uk.com/foodfacts/portionsizesfoodfactsheet.pdf. Accessed 4 Dec 2018

53. Rellinger D (2013) How to convert grams of sugars into teaspoons. https://www.canr.msu.edu/news/how_to_convert_grams of_sugars_into_teaspoons. Accessed 4 Dec 2018

54. Staffell I (2011) The energy and fuel data sheet. University of Birgmingham, Birgmingham

55. van de Kamp ME, van Dooren C, Hollander A, Geurts M, Brink EJ, van Rossum C et al (2018) Healthy diets with reduced 
environmental impact? The greenhouse gas emissions of various diets adhering to the Dutch food based dietary guidelines. Food Res Int 104:14-24. https://doi.org/10.1016/j.foodres.2017.06.006

56. Vieux F, Darmon N, Touazi D, Soler LG (2012) Greenhouse gas emissions of self-selected individual diets in France: changing the diet structure or consuming less? Ecol Econ 75:91-101. https:// doi.org/10.1016/j.ecolecon.2012.01.003

57. Birney CI, Franklin KF, Davidson FT, Webber ME (2017) An assessment of individual foodprints attributed to diets and food waste in the United States. Environ Res Lett 12(10):105008. https ://doi.org/10.1088/1748-9326/aa8494

58. Tom MS, Fischbeck PS, Hendrickson CT (2016) Energy use, blue water footprint, and greenhouse gas emissions for current food consumption patterns and dietary recommendations in the US. Environ Sys Decis 36(1):92-103. https://doi.org/10.1007/s1066 9-015-9577-y

59. Hartmann C, Siegrist M (2017) Consumer perception and behaviour regarding sustainable protein consumption: a systematic review. Trends Food Sci Technol 61:11-25. https://doi. org/10.1016/j.tifs.2016.12.006

60. Macdiarmid JI, Douglas F, Campbell J (2016) Eating like there's no tomorrow: public awareness of the environmental impact of food and reluctance to eat less meat as part of a sustainable diet. Appetite 96:487-493. https://doi.org/10.1016/j.appet.2015.10.011

61. de Bakker E, Dagevos H (2012) Reducing meat consumption in today's consumer society: questioning the citizen-consumer gap. J Agric Environ Ethics 25(6):877-894. https://doi.org/10.1007/ s10806-011-9345-z

62. Parker RWR, Blanchard JL, Gardner C, Green BS, Hartmann K, Tyedmers PH et al (2018) Fuel use and greenhouse gas emissions of world fisheries. Nat Clim Change 8(4):333-337. https://doi. org/10.1038/s41558-018-0117-x
63. Pelletier N, Audsley E, Brodt S, Garnett T, Henriksson P, Kendall A et al (2011) Energy intensity of agriculture and food systems. Annu Rev Environ Resour 36(1):223-246. https://doi. org/10.1146/annurev-environ-081710-161014

64. Araghi Y, Dijkema GPJ (2015) Alternative energy sources and energy infrastructure for Dutch greenhouses: investigating growers' preferences. In: International symposium for next generation infrastructure conference proceedings: 30 September-1 October 2014. International Institute of Applied Systems Analysis (IIASA), Schloss Laxenburg, Vienna, Austria, UCL STEaPP London, pp 199-203

65. Blackstone NT, El-Abbadi NH, McCabe MS, Griffin TS, Nelson ME (2018) Linking sustainability to the healthy eating patterns of the Dietary Guidelines for Americans: a modelling study. Lancet Planet Health 2(8):e344-e352. https://doi.org/10.1016/S2542 $-5196(18) 30167-0$

66. Naska A, Lagiou A, Lagiou P (2017) Dietary assessment methods in epidemiological research: current state of the art and future prospects. F1000Research 6:926. https://doi.org/10.12688/f1000 research.10703.1

67. Natarajan L, Pu M, Fan J, Levine RA, Patterson RE, Thomson CA et al (2010) Measurement error of dietary self-report in intervention trials. Am J Epidemiol 172(7):819-827. https://doi. org/10.1093/aje/kwq216

68. Vanham D, Leip A, Galli A, Kastner T, Bruckner M, Uwizeye A et al (2019) Environmental footprint family to address local to planetary sustainability and deliver on the SDGs. Sci Total Environ 693:133642. https://doi.org/10.1016/j.scitotenv.2019.133642

69. Huseinovic E, Winkvist A, Bertz F, Brekke HK (2014) Changes in food choice during a successful weight loss trial in overweight and obese postpartum women. Obesity 22(12):2517-2523. https ://doi.org/10.1002/oby.20895

\section{Affiliations}

\section{Alessandra C. Grasso ${ }^{1}$ (D ) Margreet R. Olthof ${ }^{1} \cdot$ Corné van Dooren $^{2} \cdot$ Miquel Roca $^{3} \cdot$ Margalida Gili $^{3}$. Marjolein Visser ${ }^{1} \cdot$ Mieke Cabout $^{1}$ - Mariska Bot ${ }^{4} \cdot$ Brenda W. J. H. Penninx ${ }^{4}$. Gerard van Grootheest ${ }^{4}$. Elisabeth Kohls ${ }^{5}$. Ulrich Hegerl ${ }^{6}$. Matthew Owens ${ }^{7}$. Ed Watkins ${ }^{7}$. Ingeborg A. Brouwer ${ }^{1}$ on behalf of the MooDFOOD Prevention Trial Investigators}

1 Department of Health Sciences, Faculty of Science, and Amsterdam Public Health Research Institute, Vrije Universiteit (VU) Amsterdam, De Boelelaan 1085, 1081 HV Amsterdam, The Netherlands

2 Netherlands Nutrition Centre (Voedingscentrum), Bezuidenhoutseweg 105, 2594 AC The Hague, The Netherlands

3 Institut Universitari d'Investigació en Ciències de la Salut (IUNICS/IDISBA), Rediapp, University of Balearic Islands, Carretera De Valldemossa km 7.5, 07122 Palma de Mallorca, Spain

4 Department of Psychiatry, Amsterdam Public Health Research Institute, and GGZ inGeest Specialized Mental Health Care, Amsterdam UMC, VU Amsterdam, De Boelelaan 1117, 1081 HV Amsterdam, The Netherlands
5 Department of Psychiatry and Psychotherapy, Medical Faculty, University Leipzig, Semmelweisstr. 10, Haus 13, 04103 Leipzig, Germany

6 Department of Psychiatry, Psychosomatics and Psychotherapy, Medical Faculty, Goethe-University Frankfurt, Heinrich-Hoffmann-Str. 10, 60528 Frankfurt a.M., Germany

7 Department of Psychology, University of Exeter, Perry Road, Exeter EX4 4QG, UK 